\title{
Lander Awarded Inaugural Breakthrough Prize
}

ERIC S. LANDER of the Massachusetts Institute of Technology and Harvard Medical School has been awarded an inaugural 2013 Breakthrough Prize, which carries a cash award of US\$3,000,000.

He was honored "for the discovery of general principles for identifying human disease genes, and enabling their application to medicine through the creation and analysis of genetic, physical and sequence maps of the human genome." He was one of the principal leaders of the Human Genome Project and is currently president and founding director of the Eli and Edythe L. Broad Institute of Harvard and MIT, professor of biology at MIT, and professor of systems biology at Harvard Medical School.

Lander earned his B.A. in mathematics from Princeton University and his Ph.D. in mathematics from Oxford University, where he was a Rhodes Scholar. He wrote his doctoral thesis on algebraic coding theory and symmetric block designs. As a mathematician he studied combinatorics and applications of representation theory to coding theory. He later taught managerial economics at Harvard Business School.

He became interested in mathematical neurobiology and began by first studying cellular neurobiology and molecular biology. These studies finally led him to genetics. He joined the Whitehead Institute for Biomedical Research in 1986. In 1987 he received a MacArthur Fellowship. In 1990 he founded the Whitehead Institute/MIT Center for Genome Research (WICGR) and later the Broad Institute, which incorporated the laboratories of WICGR.

He has received numerous awards, including the Gairdner International Award, the Max Delbrück Medal, and the AAAS Award for Public Understanding of Science and Technology. He received the Albany Medical Center Prize in Medicine and Biomedical Research and the New York Academy of Medicine Medal for Distinguished Contribu-

DOI: http://dx.doi.org/10.1090/noti1019 tions in Biomedical Science. In 2009 President Barack Obama appointed him to cochair the President's Council of Advisors on Science and Technology. He is an elected member of the U.S. National Academy of Sciences, the U.S. Institute of Medicine, and the American Academy of Arts and Sciences, and is a member of the Mathematical Association of America.

The Breakthrough Prizes in Life Sciences were founded by Apple chairman Art Levinson; Google cofounder Sergey Brin; biotech analyst, biologist, and businesswoman Anne Wojcicki;

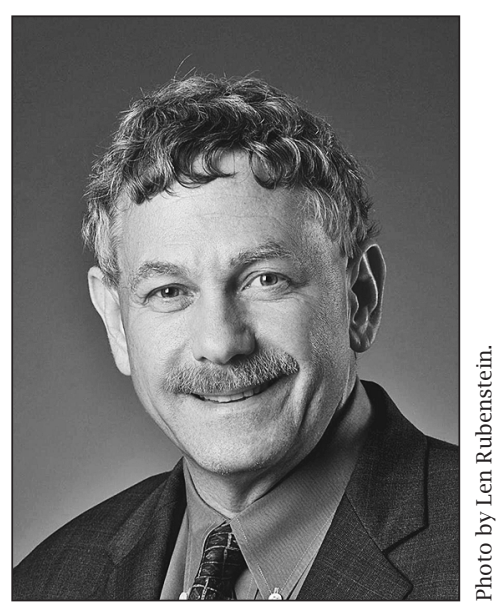

Eric S. Lander Facebook founder Mark Zuckerberg and his wife, Priscilla Chan; and entrepreneur and investor Yuri Milner to recognize excellence in research aimed at curing intractable diseases and extending human life. The prize is administered by the Breakthrough Prize in Life Sciences Foundation, a not-for-profit corporation dedicated to advancing breakthrough research, celebrating scientists, and generating excitement about the pursuit of science as a career. The prizes are awarded annually for past achievements in the field of life sciences, with the aim of providing the recipients with more freedom and opportunity to pursue even greater future accomplishments.

-Elaine Kehoe 